The Egyptian Journal of Hospital Medicine (January 2019) Vol. 74 (5), Page 1069-1074

\title{
Comparative Study for Serum Zinc and Copper Levels in Cases with Normal Pregnancy Versus Preeclampsia
}

\author{
Ahmed Saied Sayed Mohamed ${ }^{1}$, Fahd Abdelaal El-Omda ${ }^{1}$,Ahmed Taha Abdelfatah ${ }^{1}$,Mahmoud \\ Abdellatif Hashish ${ }^{2}$ \\ ${ }^{1}$ Department of Gynecology and Obstetrics, ${ }^{2}$ Clinical Pathology, Faculty of Medicine, Al-Azhar \\ University, Cairo, Egypt
}

Correspondence author: AHMED SAIED SAYED MOHAMED, Phone: 01278601420 - Email: ahmedbenny14@gmail.com

\begin{abstract}
:
Background: Preeclampsia is a leading cause of both maternal and prenatal morbidity and mortality worldwide. Preeclampsia is more common in developing countries due to women's low dietary intake of essential minerals and vitamins, micronutrients such as copper, zinc, magnesium, manganese and selenium.

Aim of work: was to investigate the levels of serum zinc and copper in preeclamptic women versus normal pregnant women.

Patients and Methods: This case-control prospective study included a total of 50 pregnant women attending the Antenatal Clinic, Department of Obstetrics and Gynecology, Al-Azhar University Hospital. Subjects were categorized into 2 groups. Group I: 25 women with preeclampsia and Group II: 25 normal pregnant women without preeclampsia who served as controls. Studied group women were subjected to the following investigations: Urine analysis for detection of albumin and measurement of the degree of proteinuria, $\mathrm{CBC}$, liver function tests, renal function tests, coagulation profiles and serum zinc and copper estimation were done. Results: have showed that preeclamptic pregnant women have low serum concentration of zinc $(\mathrm{Zn})$ and copper $(\mathrm{Cu})$ comparing to the healthy pregnant women. Zinc levels in control group was $95.7 \mathrm{mg} / \mathrm{dL}$ and in preeclamptic group $60.8 \mathrm{mg} / \mathrm{dL}$ with highly significance statistical difference $(\mathrm{p}<0.001)$. Copper levels in control group was $96.7 \mathrm{mg} / \mathrm{dL}$ and in preeclamptic group $62.9 \mathrm{mg} / \mathrm{dL}$ with highly significance statistical difference $(\mathrm{p}<0.001)$.

Concusion: It could be concluded that there are certain circumstances where preeclamptic pregnant women have low serum concentration of zinc $(\mathrm{Zn})$ and copper $(\mathrm{Cu})$ than the healthy pregnant women. This suggests the possible involvement of depleted serum trace element in the pathogenesis of preeclampsia, but we could not tell if this decrease in serum levels of $\mathrm{Zn}$ and $\mathrm{Cu}$ was a cause or a result of preeclampsia.
\end{abstract}

Key words: Zinc, Copper, Normal pregnancy nutrition, Preeclampsia.

\section{Introduction:}

Preeclampsia is one of the most important diseases of pregnancy. It complicates 7\%-10\% of all pregnancies and is a leading cause of both maternal and prenatal morbidity and mortality worldwide. Preeclampsia is defined as a combination of high blood pressure (hypertension), swelling (edema) and protein in the urine (proteinuria) developing after the 20th week of pregnancy. The etiology of this relatively common medical complication of pregnancy still unknown. Hypertensive disorders account for 40000 maternal deaths annually. It stands next to hemorrhage and embolism among pregnancy related cause of death ${ }^{(\mathbf{1})}$.

The greatest impact is in developing countries, where it accounts for $20-80 \%$ of the strikingly increased maternal mortality. Preeclampsia is more common in developing countries due to women's low dietary intake of essential minerals and vitamins. Pregnant women in developing countries have been reported to consume diets that are low in minerals and vitamins. Inadequate dietary intake might be harmful not only for the mother but also for the growing 
fetus. The pathogenesis of adverse pregnancy outcomes including preeclampsia and fetal growth restriction have been shown to be associated with oxidative stress. Micronutrients such as copper, zinc, magnesium, manganese and selenium are involved in the antioxidant defense as cofactors of enzymes. Superoxide dismutase is an antioxidant enzyme that contains the trace elements zinc and copper ${ }^{(2)}$.

Copper is a trace mineral essential micronutrient and is required for the formation of many enzymes, with important role in the human body. It has an important role in pregnancy for the formation of a wide variety of enzymatic and other processes within the developing fetus. During pregnancy, many changes occur in copper levels and transport in both mother and fetus. The serum copper increases in early pregnancy and continues to rise to reaching levels at full term approximately twice those found in nonpregnant women. Maternal age does not influence copper serum levels. Some analyses have shown substantially lower plasma concentrations of copper in pathological conditions diagnosed during the first trimester of pregnancy (spontaneous abortion, threatened abortion, missed abortion and blighted ovum). No significant differences in maternal plasma blood copper concentrations have been found in pathological conditions (threatened abortion, threatened preterm delivery and pyelonephritis) diagnosed in the second trimester of pregnancy. Tendencies to higher plasma copper concentrations, however statistically insignificant, can be observed in other pathological conditions during the third trimester (gestosis, intrauterine growth retardation, preterm labour). Copper is delivered to the developing foetus via specific transporters in the placenta that are regulated by the mother's estrogen and insulin levels. These findings have implications for better understanding of preeclampsia. Intrauterine growth retardation, the development of babies born to mothers with gestational diabetes and some genetic disorders (3).

Zinc concentrations in gravidae showed a gradual fall during the first and second trimesters. From the 25 th week of gestation until delivery there is a leveling out of mean zinc values. No correlations between serum zinc, urinary excretion of estriol were found. Women with mature infants born by normal delivery showed significantly higher serum zinc during pregnancy than women with abnormal deliveries and/or abnormally developed infants. Some women with abnormal zinc level showed congenital malformations. Adiabatic woman gave birth to an immature infant with multiple skeletal malformations. She showed the lowest serum zinc in the 21st week, and at the same time a very low alkaline phosphatase activity. Her serum proteins and serum HCS were normal (4).

\section{Aim of the Work}

The aim of the current work was to investigate the levels of serum zinc and copper in preeclamptic women versus normal pregnant women.

\section{Patients and Methods:}

This case-control prospective study included a total of 50 pregnant women attending the Antenatal Clinic, Department of Obstetrics and Gynecology, Al-Azhar University Hospital. Approval of the ethical committee and a written informed consent from all the subjects were obtained. This study was conducted between October 2017 till October 2018. The study was approved by the Ethics Board of Al-Azhar University.

Subjects were categorized into 2 groups. Group I: 25 women with preeclampsia and Group II: 25 normal pregnant women without preeclampsia who served as controls.

Studied group women were subjected to the following investigations: urine analysis for detection of albumin and measure the degree of proteinuria, CBC, liver function tests, renal function tests, coagulation profiles and serum zinc and copper estimation.

\section{Inclusion criteria:}


Age 22-30 years, third trimester of pregnancy with a single fetus and gestational age above 36 weeks.

Preeclampsia was defined as a blood pressure of 140/90 or more on two occasions each 6 hours apart associated with proteinuria of at least 300 mg per 24 hours or at least $1+$ on dipstick testing. Severe preeclampsia was defined as a blood pressure of $160 / 110 \mathrm{mmHg}$ or above measured on two occasions each 6 hours apart. A detailed family and medical history were taken.

\section{Exclusion criteria:}

Patients with history of medical diseases as chronic hypertension, diabetes, renal, cardiovascular and liver diseases, and with obstetric complications as multiple gestations intrauterine fetal death and ante partum hemorrhage were excluded from the study.

Complete history taking: personal, Obstetrical, menstrual and associated medical problems histories were taken. History of pregnancy induced hypertension without proteinuria.
Clinical examination: general and obstetrical examinations were done.

\section{Ultra sound:}

Was done for fetal viability, and fetal age, site of placenta, number of fetus and amount of liquor.

\section{Laboratory investigations:}

Urine analysis for detection of albumin and measurement of the degree of proteinuria, CBC, liver function tests, renal function tests, coagulation profiles and serum zinc and copper estimation were done.

\section{Result:}

This case-control prospective study included a total of 50 pregnant women who were categorized into 2 groups. Group I: 25 women with preeclampsia and Group II: 25 normal pregnant women without preeclampsia who served as controls.

The data collected from all patients were illustrated in the following tables:

Table (1): comparison between control cases and preeclamptic cases regarding demographic data:

\begin{tabular}{|c|c|c|c|}
\hline Age of mothers (years) & $26.2( \pm) 5$ & $22.6( \pm) 6.7$ & $>0.05$ \\
\hline Gestational age (weeks) & $32.5( \pm) 3.9$ & $33.1( \pm) 2.8$ & $>0.05$ \\
\hline Parity & $1( \pm) 0.7$ & $1( \pm) 0.8$ & $>0.05$ \\
\hline Gravidity & $2( \pm) 0.8$ & $2( \pm) 0.7$ & $>0.05$ \\
\hline
\end{tabular}

p>0.05=non signifiecant

There is no statistically signifiecant difference could be detected.

Table (2): Blood pressure parameters of studied groups:

\begin{tabular}{|c|c|c|}
\hline & Control & Preeclamptic \\
\hline Systolic blood pressure (Units) & $119.6 \pm 10.5$ & $160 \pm 20$ \\
\hline Diastolic blood pressure (Units) & $68.5 \pm 7$ & $104.3 \pm 8.5$ \\
\hline Significance & $<0.01$ & 0.01 \\
\hline
\end{tabular}

$\mathbf{P}<0.01=$ highly significant difference

In normal pregnant women, serum $\mathrm{Zn}$ levels were found from $50-120 \mathrm{mg} / \mathrm{dL}$ and serum $\mathrm{Cu}$ from $80-155$ $\mathrm{mg} / \mathrm{dL}$.

Table (3): Serum zinc level of the studied groups (mg/dl):

\begin{tabular}{|l|l|l|l|}
\hline & \multicolumn{1}{|c|}{ Mean (Units) } & \multicolumn{1}{c|}{ SD } & \multicolumn{1}{c|}{ Range } \\
\hline Control cases (25) & 95.7 & 10.4 & $82-115$ \\
\hline Preeclamptic cases(25) & 60.8 & 12.8 & $33-85$ \\
\hline Significance & $\mathrm{P}<0.001$ & $\mathrm{P}<0.001$ & $\mathrm{P}<0.001$ \\
\hline
\end{tabular}

$\mathbf{P}<0.001=$ highly significant difference 
Table (4): Serum copper level of the studied groups ( $\mathrm{mg} / \mathrm{dl})$ :

\begin{tabular}{|c|c|c|c|}
\hline & Mean (Units) & SD & Range \\
\hline Control cases (25cases) & 96.7 & 8.8 & $67-115$ \\
\hline $\begin{array}{c}\text { Preeclamptic } \\
\text { cases(25cases) }\end{array}$ & 62.9 & 12.9 & $35-90$ \\
\hline Significance & $\mathrm{P}<0.001$ & $\mathrm{P}<0.001$ & $\mathrm{p}>0.001$ \\
\hline
\end{tabular}

$\mathbf{P}<0.001=$ highly significant difference

\section{Discussion:}

The pregnancy syndrome which called preeclampsia is one of most serious complications of pregnancy. It is also an important cause of maternal and prenatal mortality. The etiology of this relatively common medical complication of pregnancy however remains unknown but numbers of factors and theories have been identified including genetic, immunological and placental. The study was designed to assess the role of trace metals in the pathogenesis of preeclampsia and rather their deficiency may be implicated in the occurrence and progression of this disease ${ }^{(5)}$.

The demographic data and clinical parameters of the studied groups are given in table (1) and as regard mean maternal age in control group $(26.2 \pm 5)$ and in preeclamptic group $(22.6 \pm 6.7)$ with no significant statistical difference ( $>0.05)$. As regard mean gestational age in control group was $(32.5 \pm 3.9)$ and in preeclamptic group $(33.1 \pm 2.8)$ with no significant statistical difference $(\mathrm{p}>0.05)^{(6)}$. As regard parity the control group was $(1 \pm 0.7)$ while in preeclampsia $(1 \pm 0.8)$ and gravidity in control group is $(2 \pm 0.8)$ and in preeclampsia $(2 \pm 0.7)$ the two demographic data with no significance statistical difference $(p>0.05)$. However, as regard systolic and diastolic blood pressure in table (2), the systolic blood pressure in control group 119.6 \pm 10.5 while in preeclampsia is $160 \pm 20$ with highly significance statistical difference $(\mathrm{p}<0.01)$.moreover the diastolic pressure in control is $(68.5 \pm 7)$ while in preeclampsia $(104.3+8.5)$ with highly significance statistical difference $(\mathrm{p}<0.01)^{(7)}$.
As regard zinc levels in cases of our study we show in table (3) the mean serum concentration in control group 95.7and in preeclamptic group 60.8 with highly significance statistical difference $(p<0.001)$. The result of this study regard zinc level are in agreement with the result of Ihan et $\boldsymbol{a l} .{ }^{(8)}$ as they carried out a study to measure changes of trace metals including zinc. There study comprised from 24 normal non pregnant, 30 normal pregnant, 21 preclamtic $3^{\text {rd }}$ trimester pregnancy. The mean serum zinc in normal pregnant is $125 \pm 24.23$ and in preeclamptic cases $82.9 \pm 28.9$ with highly significance statistical difference $(\mathrm{p}<0.001)$.

Significance changes in serum zinc have been documented during normal pregnancies. In preeclampsia decrease serum zinc levels have been determined, low serum zinc concentration have been suggested to be at least partially due to reduced estrogen and zinc binding protein level(8). Also serum cortisol level increases during normal pregnancy and much more high in preeclampsia which again reduce zinc serum level ${ }^{(9)}$.

Moreover, the result of this study regard serum zinc agreed with result of Yildiz $\boldsymbol{e t}$ al. ${ }^{(\mathbf{1 0 )}}$ as they carried out a study on 32 preeclamptic cases and 28 healthy pregnant cases and 25 non pregnant cases. Their estimation of serum zinc in preeclamptic cases $0.792 \pm 0.180 \mathrm{mg} / \mathrm{dl}$ while in healthy pregnant cases $1.086 \pm 0.199$ with non significance statistical difference $(p>0.05)$ between preeclamptic cases and healthy pregnant cases while highly significance statistical difference between preeclamptic cases and non pregnant cases $(\mathrm{p}>0.001){ }^{(\mathbf{1 0})}$. 
On other hand, our study does not agreed with the result of Mehmet et $\mathbf{a l} .{ }^{(11)}$ they carried out study of 24 preeclamptic cases and 44 normotensive pregnant cases, mean serum zinc in preeclamptic cases $15.53 \pm 4.92 \mathrm{mg} / \mathrm{g}$ while in normotensive cases $11.93 \pm 3.11 \mathrm{mg} / \mathrm{g}$ with statistical significance $(\mathrm{p}<0.003)$ which shows increase serum zinc in preeclamptic group. Regarding copper level our result in table (4), the mean copper concentration level in control cases 96.7 while in preeclamptic group 62.9 with highly significance statistical difference $(\mathrm{p}<0.001)$.

The result of our study agreed with the result of Xie et $\boldsymbol{a l} .{ }^{\left({ }^{(12)}\right.}$ as they carried out the study to measure copper level as an index for placental function in healthy pregnant women and preeclamptic women and they found that in preeclampsia there is placental insufficiency and also decrease serum copper and decrease in several copper containing enzymes which are produced and stored in placenta ${ }^{(\mathbf{1 2})}$.

However, the results of present study as regard copper are not agreed with the results of Ihan $\boldsymbol{e t}$ $\boldsymbol{a l}^{\left({ }^{(8)}\right.}$ as they carried out the study on 24 normal non pregnant wpmen, 30 normal pregnant women, and 21 preeclamptic women in $3^{\text {rd }}$ trimester. Measurement of serum copper level was significantly increased in normal pregnancy and pre-eclamptic women compared to non pregnant control group, and difference between pre-eclamptic cases and normal pregnant women is statistical significance $(\mathrm{p}<0.05)$,they explained that estrogen in part participate in increasing serum copper conc. ${ }^{(13)}$.

In pregnancy by induction of copper carrying protein. Little is known about determinants of maternal trace metal metabolism in uncomplicated and pathological pregnancies. The scarcity of fundamental information on trace metal metabolism in pregnancy does not allow extensive discussion of potential biological mechanism that may account for their finding. Also limited information per training to maternal dietary intake as well as trace metal content of food consumed by this population limited their ability to assess diet intake of these micronutrients and risk of preeclampsia. In this study the rock curve was used to calculate the best cut of value for zinc and copper as shown in Roberts et al. ${ }^{(14)}$ by calculating the positive and negative predictive value, specificity, sensitivity and accuracy for each trace metal, it was found that:

- Copper has best sensitivity and accuracy.

- Zinc has best negative test due to high specificity and negative predictive value.

\section{Conclusion:}

It could be concluded that there are certain circumstances where preeclamptic pregnant women have low serum concentration of zinc $(\mathrm{Zn})$ and copper $(\mathrm{Cu})$ than the healthy pregnant women. This suggests the possible involvement of depleted serum trace element in the pathogenesis of preeclampsia, but we could not tell if this decrease in serum levels of $\mathrm{Zn}$ and $\mathrm{Cu}$ was a cause or a result of preeclampsia.

\section{References:}

1. Al-Jameil N, Aziz Khan F, Fareed $M$ et al. (2014): A brief overview of preeclampsia. J. Clin. Med. Res., 6(1): 1-7.

2. Awadallah SM, Abu-Elteen KH, Elkarmi AZ et al. (2004): Maternal and cord blood serum levels of zinc, copper and iron in healthy pregnant Jordanian women. J. Trace. Elem. Exp. Med., 17:1-8

3. Akhtar S, Begum $S$ and Ferdousi $S$ (2011): Calcium and zinc deficiency in preeclamptic women. J Bangladesh Soc Physiol., 9(3): 422-436.

4. Kamru S, Aydin S, Simsek M et al. (2003): Comparison of serum copper, zinc, calcium and magnesium levels in preeclamptic and healthy pregnant women. Biol. Trace. Elem. Res., 94(2):105-12.

5. Mistry HD, Williams PJ (2011): The importance of antioxidant micronutrients in pregnancy. Oxidat. Medi. Cellular. Longev., 2011:841749.

6. Akinloye O, Oyewale OJ and Oguntibeju OO (2010): Evaluation of trace elements in pregnant women withpre-eclampsia. Afr. J. Biotechnol., 9(32): 5196-5202. 
7. Cetin I, Berti C and Calabrese S (2010): Role of micronutrients in the periconceptional period. Hum. Reprod. Update, 16(1):80-95.

8. Ihan N, Ilhan N and Simsek M (2002): The changes of trace elements, malondialdehyde levels and superoxide dismutase activities in pregnancy with or without preeclampsia. Clin. Biochem., 35(5):393-7.

9. Laresgoiti-Servitje E, Gómez-López N and Olson DM (2010): An immunological insight into the origins of pre-eclampsia. Hum. Reprod. Update, 16(5):510-525.

10. Yildiz A, Oylumlu M, Ozler A et al. (2004): New inflammatory markers in preeclampsia: echocardiographic epicardial fat thickness and neutrophil to lymphocyte ratio. Clin. Exp. Hypertens., 36:503-07.
11. Mehmet AA, Ali AA, Ali NI et al. (2004): Zinc, parity, infection, and severe anemia among pregnant women in Kassla, eastern Sudan. Biol. Trace. Elem. Res., 140:-28490.

12. Xie L, Mouillet JF, Cu T et al. (2014): C19MC MicroRNAs Regulate the Migration of Human Trophoblasts. Endocrinology, 155(12):4975-85.

13. Mistry HD, Williams PJ (2011): The importance of antioxidant micronutrients in pregnancy. Oxid. Med. Cell Longev., 11: 41-49.

14. Roberts JM, Balk JL, Bodnar LM et al. (2003): Nutrient involvement in preeclampsia. J. Nutr., 133(5):1684-1692. 